\title{
ORGANIZAÇÃO DO TRABALHO E FORMAÇÃO DOS TRABALHADORES NUMA MICROÁREA DO PROGRAMA SAÚDE NA ESCOLA
}

\author{
A.L. GOMES ${ }^{1}$, M.F. VIEGAS ${ }^{2}$ \\ Universidade de Santa Cruz do Sul \\ moacirfviegas@gmail.com²
}

Artigo submetido em 26/03/2018 e aceito em 27/11/2019

DOI: $10.15628 /$ holos.2019.7136

\section{RESUMO}

O Programa Saúde na Escola (PSE) situa-se no contexto das políticas públicas de saúde implementadas nas primeiras décadas desse século, as quais têm ampliado as possibilidades de acesso à informação e aos serviços de saúde dos sujeitos sociais, constituindo importante iniciativa para a ampliação da cidadania e dos direitos sociais. Apesar do significativo número pesquisas sobre o Programa, a formação dos profissionais que nele atuam, condição para seu sucesso, tem recebido muito pouca atenção. A partir de nossa experiência como profissionais em programas de educação e saúde e como pesquisadores da área da educação, nosso objetivo no presente artigo é descrever e analisar as práticas educativas de formação dos trabalhadores que atuam no
PSE na microárea de um município de médio porte do Vale do Rio Pardo, no Rio Grande do Sul. Realizado entre os anos de 2014 e 2016, com metodologia qualitativa e análise documental, o estudo teve como sujeitos profissionais da área da saúde e da educação, com os quais foram aplicadas entrevistas que posteriormente foram objeto da análise de seu conteúdo. Os resultados revelam a precariedade das condições de formação dos profissionais que atuam no PSE e suas iniciativas para superar as limitações impostas por estas condições, além de reafirmar a importância do Programa para a realidade escolar.

PALAVRAS-CHAVE: Educação e saúde, Trabalho e saúde, Educação e trabalho, Programa Saúde na Escola, Formação para o trabalho.

\section{LABOR ORGANIZATION AND FORMATION OF WORKERS IN A MICROREGION OF THE SCHOOL HEALTH PROGRAM}

\section{ABSTRACT}

The School Health Program (SHP) is in the context of public policies of health implemented on the first decades of this century, which have broadened the possibilities of access to information and to the health services of local subjects, composing an important initiative to the broadening of citizenship and social rights. Despite the significant number of researches about the Program, the formation of the professionals that work on it, a condition to its success, has not received a lot of attention. Starting from our experiences as professionals in education and health programs and as researchers on the education field, our goal in this article is to describe and analyse the educative practices in the formation of workers that act on the SHP in a microregion of a medium sized town at the Vale do Rio Pardo, Rio Grande do Sul. Made between 2014 and 2016, with a qualitative methodology and documental analysis, the research had as its subjects professionals of the health and education area, with which were applied interviews that eventually were object of content analysis. The results showed the poor formation condition of the professionals that act on the SHP and their initiatives to overcome the limitations imposed by these conditions, as well as reaffirming the importance of the Program to the school reality.

KEYWORDS: Education and health, Work and health, Education and work, Social Health Program, Work formation. 


\section{INTRODUÇÃO}

O interesse pelo tema desse artigo nasceu de nossas experiências em programas de educação em saúde vivenciadas desde a graduação em Enfermagem, quando chamou-nos a atenção a aceitação e adesão das crianças e jovens. Acreditamos que crianças e adolescentes com acesso à formação em saúde terão melhores possibilidades de enfrentar problemas relacionados ao adoecimento e estenderão esses conhecimentos à comunidade em que estão inseridos.

A principal meta da promoção da saúde é detectar os problemas precocemente, de modo que eles possam ser prevenidos ou tratados o mais cedo possível. Tendo em vista a construção de saberes e valores no decorrer da infância, as crianças estão mais abertas para receber, compreender e assimilar práticas saudáveis para a vida, dentre essas, o cuidado com o corpo, o cuidado com o outro, o compartilhar, a atividade física e as qualidades do alimento (Mattos, Veronesi \& Silva Junior, 2013).

A partir desse interesse e enquanto profissionais envolvidos com práticas educativas e a pesquisa em educação, emergiu-nos o questionamento sobre a qualificação dos sujeitos envolvidos nesses programas e daí o desejo de compreender o processo de formação dos trabalhadores da educação e da saúde atuantes no Programa Saúde na Escola (PSE). Apesar da formação dos profissionais ter ocupado lugar importante nas políticas de saúde desse século, na prática segue-se enfrentando os mesmo problemas de insuficiência no número de trabalhadores e uma organização do trabalho que dificulta a realização de práticas educativas para as atividades dos programas. Em geral, a formação dos trabalhadores não ultrapassa as tradicionais capacitações pontuais, de conteúdo prescritivo e descontextualizadas e, portanto, sem eficácia (Ceccim, 2005). Além disso, a recente crise do país tem contribuído para minar os recursos para que essa dimensão das políticas seja atendida de forma adequada.

A pesquisa se justifica também pela quase inexistência de estudos sobre o PSE que tenham como tema central a formação dos profissionais da educação e da saúde que atuam no Programa. Entre as 103 dissertações e 15 teses do Banco de Teses e Dissertações da Capes sobre o assunto, apenas uma (Marinho, 2014) tem como temática principal a formação dos trabalhadores que atuam no Programa. A mesma situação verificamos na base de dados do Scielo Brasil, onde não encontramos qualquer artigo com esse perfil. Tal carência de estudos causa-nos certa estranheza, na medida em que a formação dos trabalhadores é estratégica para o sucesso do Programa.

A pesquisa foi realizada entre os anos de 2014 e 2016 e teve como objetivo principal descrever e analisar as práticas educativas de formação dos trabalhadores que atuam no Programa Saúde na Escola na microárea de um município de médio porte do Vale do Rio Pardo, no Rio Grande do Sul.

Após um breve resumo da história da educação e saúde nas escolas no Brasil, discorremos sobre o contexto em que se insere o Programa Saúde na Escola, destacando a organização do trabalho e a política pública que criou o Programa. Na análise das informações, iniciamos pela descrição da organização do trabalho no PSE na microárea investigada, para em seguida discutirmos os processos educativos em que estão inseridos os trabalhadores. 


\section{REVISÃO BIBLIOGRÁFICA}

\subsection{Educação em saúde voltada às escolas no Brasil}

Conforme Silva e Bodstein (2016), as práticas de saúde escolar têm início no país no começo do século XX e são marcadas pela lógica higienista, preventista e comportamental, com o setor saúde determinando unilateralmente os componentes normativos e os conteúdos "sobre o que deveria ser feito e discutido" nas escolas (p. 1778). A saúde, entendida como condição para a aprendizagem, implicava a adoção de hábitos saudáveis, responsabilizando-se os pobres por sua miséria e pela insalubridade das cidades.

Esse modelo perdurou por quase todo o século XX e mesmo as inovadoras políticas do nosso século encontram dificuldades para superá-lo totalmente. No sentido de não nos estendermos em demasia na descrição dos principais fatos históricos que marcam a trajetória da educação em saúde nas escolas do país, apresentamos a seguir uma figura que resume os principais momentos da mesma.

Desenvolvimento da educação em saúde nas escolas no Brasil

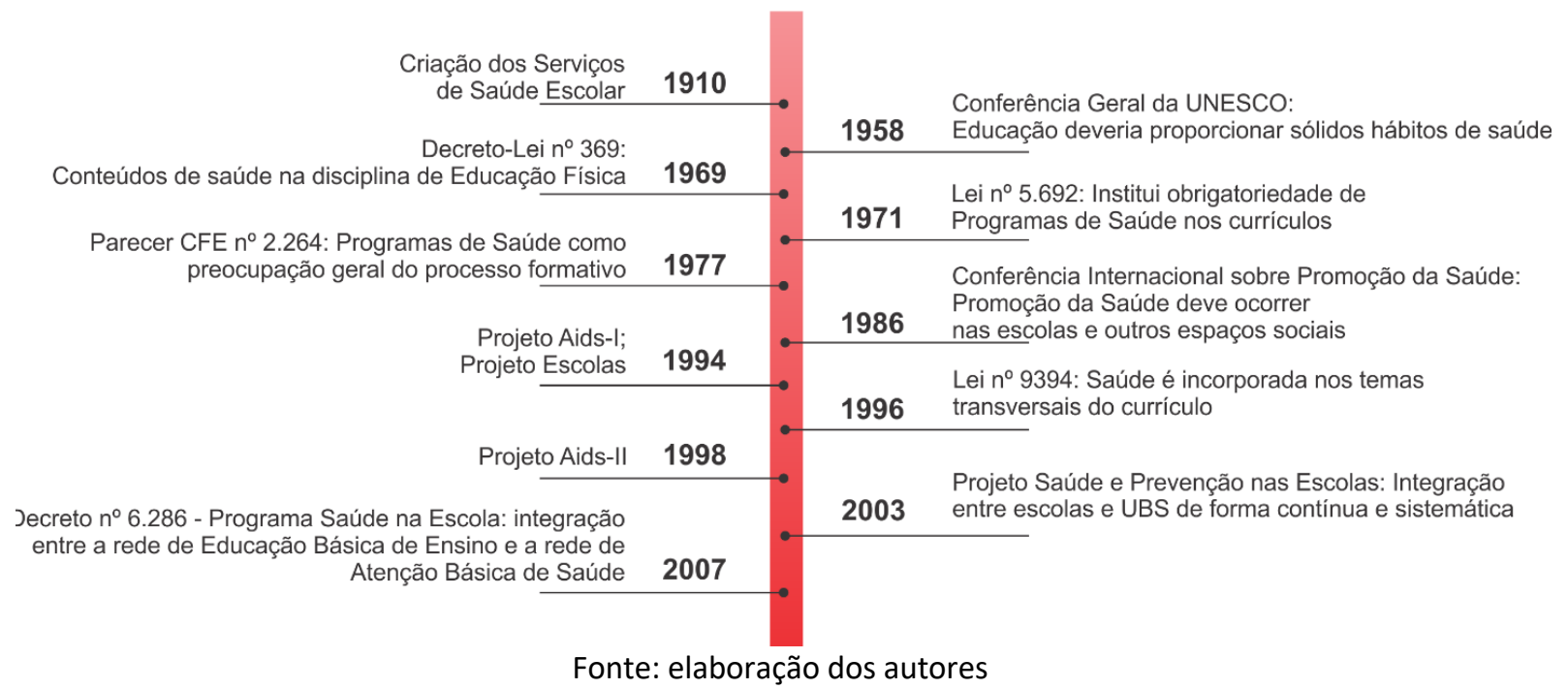

Entre esses momentos, cabe destacar a Lei no 5.692, que instituiu a obrigatoriedade de Programas de Saúde nos currículos dos estabelecimentos de 1 e 2 음 Graus. Entretanto, a educação em saúde deveria ocorrer apenas na disciplina de Educação Física.

O Programa Saúde na Escola (PSE) é instituído em 2007, por meio do Decreto Interministerial no 6.286, com o objetivo de integrar as redes de educação e saúde nos territórios de alocação de 
Estratégias de Saúde da Família (ESF), dessa forma ampliando "o alcance e o impacto de suas ações relativas aos estudantes e suas famílias, otimizando a utilização dos espaços, equipamentos e recursos disponíveis" (Brasil, 2007). Surge como uma política pública que objetiva contribuir para a formação integral dos estudantes da rede de educação básica por meio do estimulo à prevenção, promoção e atenção integral a crianças, adolescentes e jovens, em ações desenvolvidas no ambiente escolar e na unidade de saúde.

O PSE tem como desafio superar ações pautadas no modelo biomédico, tendo como perspectiva a promoção da saúde e como princípio a construção e controle social da política por meio da participação ativa dos sujeitos envolvidos. Surgido no contexto de implementação da Política Nacional de Humanização (PNH), o Programa deve alinhar-se ao espírito da mesma, que propugna o desenvolvimento de trocas solidárias e comprometidas entre as equipes, o engajamento, a autonomia e o protagonismo dos trabalhadores nos espaços de produção da saúde (Filho e Barros, 2012; Hennington, 2008). É relevante destacar ainda, quanto a PNH, a ênfase na mudança da lógica da racionalidade técnico-burocrática e da compartimentalização e individualização dos processos de trabalho, assim como a inseparabilidade entre as práticas e a gestão do cuidado (Benevides \& Passos, 2005).

\subsection{Os trabalhadores e o trabalho em saúde}

Na esteira do crescimento das atividades de serviços e de políticas públicas como o Sistema Único de Saúde (SUS) e a PNH, a saúde foi o setor que apresentou maior ampliação da oferta de empregos na primeira década do século XXI. Os trabalhadores representavam, em 2009, 4,8\% de toda a força de trabalho ocupada no Brasil (Dedecca \& Trovão 2013).

A maneira atual da organização do trabalho em saúde reproduz as relações de produção capitalistas, onde os trabalhadores enfrentam grandes pressões por produtividade, flexibilização da contratação e relações verticais entre eles e a gestão. Em nível internacional, as reformas nos sistemas de saúde ocorreram num contexto de globalização e financeirização da economia, acompanhados de privatizações, desregulamentação e precarização das condições de trabalho, diminuição da proteção social e redução dos serviços públicos (Hirata, 2011; Antunes, 2010), processos que se encontram em contradição com as intenções de políticas públicas como o PSE. Desse modo, o setor saúde tem convivido com a insuficiência de recursos, o que incide na qualidade do serviço prestado (Dedecca \& Trovão, 2013) e, no que mais nos importa nesse artigo, no baixo investimento em qualificação dos trabalhadores.

A força de trabalho do setor saúde é composta por ampla maioria de mulheres. Apesar das cada vez mais intensas lutas pela igualdade de gêneros, o trabalho da mulher, que ocupa a maioria das funções no setor de serviços, ainda sofre com a desvalorização, com o predomínio da concepção de que suas atividades são "uma extensão do feminino por remeter a cuidado, assistência e serviço" (Pinsky, 2013, p. 504), onde suas qualificações são entendidas como naturais.

Cabe ressaltar a precária situação de trabalho dos Agentes Comunitários de Saúde (ACS), por serem fundamentais nas ações comunitárias de prevenção à saúde na comunidade. Esses profissionais sofrem com contratos temporários e sem muitos dos diretos reconhecidos em outras profissões. Recentemente regulamentada (Brasil, 2018), a profissão de ACS teve vetada questões 
importantes, como a jornada de trabalho de 40 horas semanais, a obrigatoriedade de estados e municípios oferecerem curso técnico com carga horária mínima de 1.200 horas e a indenização de transporte ao trabalhador para o exercício de suas atividades, além da obrigatoriedade de realização de cursos de formação introdutória e continuada a cada dois anos, durante a jornada de trabalho.

\subsection{A Formação dos trabalhadores do Programa Saúde na Escola}

A Portaria Interministerial no 1.055 de 2017 atribuiu aos ministérios da Educação e da Saúde a responsabilidade de "subsidiar a formulação das propostas de formação dos profissionais de saúde e da educação básica para a implementação das ações" (Art. 8으, III) do PSE, de maneira contínua e permanente. Para Miccas e Batista (2014), isso implica "a necessidade de impulsionar o ensino profissional de modo que o perfil do trabalhador seja voltado para a integralidade do cuidado e permanente reestruturação de seus conhecimentos a partir da problematização e demandas internas sob a lógica da EPS ${ }^{1 \prime \prime}$ (p. 172).

As estruturas de formação e os materiais didático-pedagógicos oriundos da parceria entre educação e saúde objetivam auxiliar na implantação de "planejamento, monitoramento e avaliação do PSE, no qual o público-alvo são os integrantes da saúde e educação que compõem os Grupos de Trabalho Intersetoriais (GTIs)" e a "avaliação das condições de saúde, de promoção da saúde e prevenção a riscos e agravos" (Brasil, 2011, p. 18), cujo público-alvo são os profissionais das equipes de Saúde da Família, profissionais das unidades de saúde, profissionais das escolas e jovens educandos.

Como parte da política, são propostas então cinco estratégias para a implementação dessas ações: 1) Formação do Grupo de Trabalho Intersetorial; 2) Formação de Jovens Protagonistas; 3) Formação de profissionais da educação e saúde através de atividades de educação permanente envolvendo os sujeitos da equipe de saúde e da escola; 4) Curso de Prevenção do Uso de Drogas para Educadores de Escolas Públicas e 5) Rede Universidade Aberta do Brasil, que tem como objetivo "estabelecer grupo permanente de instituições públicas de educação superior dedicadas à formação continuada, semipresencial, de profissionais da rede pública da educação básica e da atenção básica em saúde (ESF)" (Brasil, 2011, p. 19).

Em documento conjunto dos Ministérios da Educação e Saúde intitulado “Orientações sobre o Programa Saúde na Escola para a elaboração dos Projetos Locais", a educação permanente e a capacitação dos profissionais de educação e saúde e de jovens é apresentada como essencial para o êxito do desenvolvimento do Programa.

Conforme Barbosa, Ferreira e Barbosa (2012), na educação permanente do profissional de saúde o processo ensino-aprendizagem não deve restringir-se à mera transferência de conteúdos técnicos, normas e protocolos, e precisa considerar as experiências profissionais e o conhecimento pré-existente dos sujeitos. Para Miccas e Batista (2014, p. 171), o pressuposto da educação

${ }^{1}$ Educação Permanente em Saúde. 
permanente em saúde é "educar no" e "para o" trabalho, constituindo-se num processo de aprendizagem ao longo da carreira, realizado durante as atividades laborais.

\section{METODOLOGIA}

Considerando a temática escolhida, optamos pela metodologia de estudo qualitativa, de caráter descritivo e exploratório, com enfoque crítico-participativo. A escolha da microárea de realização da pesquisa se deu por sugestão da Coordenadora Municipal do Programa, pois, segundo a mesma, tratava-se de local onde tinha com bom funcionamento. A micro área envolve uma Estratégia Saúde da Família, uma Escola Municipal de Educação Infantil (EMEI) e uma Escola Municipal de Ensino Fundamental (EMEF), as quais possuem, juntas, 727 alunos.

Como sujeitos de pesquisa selecionamos, tendo como critério sua maior participação no Programa, sete trabalhadoras. Na área da saúde, integraram a pesquisa a responsável pela Coordenação Municipal, além de uma enfermeira, uma auxiliar de saúde bucal e uma odontóloga que atuam na mesma ESF. Nas unidades escolares entrevistamos duas orientadoras educacionais e a diretora da EMEI. Realizamos também entrevistas informais com a Vice-Coordenadora Municipal do Programa. As entrevistas foram gravadas e posteriormente analisadas com apoio na metodologia de análise de conteúdo.

Todos os sujeitos concordaram em participar do estudo, formalizando-o por meio da assinatura do Termo de Consentimento Livre e Esclarecido, aprovado pelo Comitê de Ética em Pesquisa da Universidade, Parecer 1.172.690, CAAE no 43399414.0.0000.5343.

\section{RESULTADOS E DISCUSSÃO}

\subsection{Organização e condições de trabalho no PSE}

No sentido de facilitar a compreensão das informações que seguem, apresentamos um esquema com a forma como se estrutura o PSE no município, destacando a microárea onde a pesquisa foi realizada.

Organização do Programa

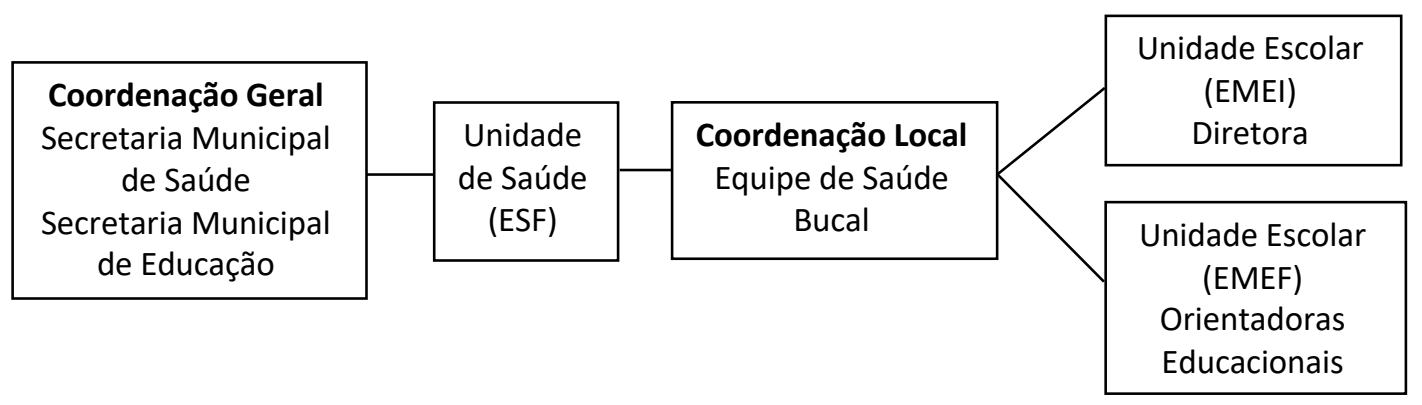

Fonte: elaboração dos autores 
Como mostra o esquema acima, em nível municipal a Coordenação e Vice-Coordenação do Programa são exercidas, respectivamente, pelas secretárias da Saúde e da Educação e em nível local é coordenado pela equipe de saúde bucal. O Grupo de Trabalho Intersetorial da microárea integra, além dessa última, as representantes das duas unidades escolares, que são a diretora da EMEI e duas orientadoras educacionais da EMEF.

A organização do trabalho ocorre de modos distintos nas unidades básicas de saúde e nas ESF, o que tem origem em seus diferentes objetivos. Enquanto as primeiras possuem um viés assistencialista, centrado na figura do profissional médico, sem vínculo com a comunidade, a ESF tem como foco a promoção da saúde e a prevenção por meio do estabelecimento de vínculos com a comunidade assistida.

Nas unidades de saúde municipais onde há equipe de saúde bucal (composta por um(a) odontólogo(a) e um(a) auxiliar de saúde bucal), a coordenação fica sob a responsabilidade da mesma. Onde não há, ela deve ser exercida por um(a) enfermeiro(a). No caso da realidade investigada, a coordenação é realizada pela odontóloga. Segundo esta, as atividades são planejadas no início do semestre, quando a equipe de saúde bucal se reúne com as responsáveis pelo PSE nas unidades escolares para discutir as demandas. Na sequência, as trabalhadoras vão vendo "o que dá para fazer e o que não dá" e assim as ações "não têm período pré-determinado" para ocorrer: "é conforme vai indo que a gente vai se reunindo e resolvendo como vai fazer". Acrescenta que há dias em que a demanda de pacientes na unidade de saúde leva à desmarcação do que estava planejado.

Assim, como afirma a diretora da EMEI, o planejamento se dá de modo bastante informal: "eu vou um pouquinho lá, ela [a odontóloga] vem um pouquinho aqui, pela proximidade, né!?", não havendo uma agenda prévia de reuniões: "quando surge a necessidade, a gente se conversa... estou precisando disso, estou precisando daquilo". Esse caráter espontâneo do planejamento foi observado também no estudo feito por Marinho (2014), para quem as ações do Programa são realizadas sem que haja "tempo definido para acontecer (...)" (p. 173).

O Núcleo Gestor local, como podemos perceber, compõe-se, na prática, de forma bastante restrita. As ações são planejadas em conversas da Coordenação do Programa com cada uma das unidades escolares, separadamente, e não há participação de professores que atuem em sala de aula e de representantes da comunidade.

O Programa encontra grande dificuldade de poder contar com profissionais da saúde para a realização das atividades, pois, conforme relato da Coordenadora Local, enfermeiros, médicos, odontólogos e técnicos de enfermagem se encontram sobrecarregados com ações como realização de consultas, exames, procedimentos, dispensação de medicação e atividades administrativas, não dispondo de tempo para o PSE. E como as atividades ocorrem, via de regra, no ambiente escolar, é a equipe de saúde bucal que precisa "arranjar uma brecha" em sua agenda para se deslocar às escolas. Ou isso é feito pelos ACS que originalmente exerciam algum tipo de atividade junto às escolas, mesmo que eles também já estejam sobrecarregados de atribuições.

A Coordenadora Municipal reforça essa percepção, ao afirmar que nas áreas de UBS “o Programa vai muito devagar porque não tem uma enfermeira, não tem um técnico superior que faça esse trabalho", ela própria dispondo de apenas cinco horas semanais. Acredita que o êxito do 
Programa depende da existência de um profissional que possa dedicar 40 horas ao mesmo, situação que ocorre, segundo afirma, nos municípios que são referência nacional. Diz que se tivesse " 20 horas só para o PSE (...), daria para fazer mais coisas. Então, com o tempo que a gente tem, até que a gente faz bastante"

A fragmentação e a sobrecarga de trabalho aliadas à vasta demanda de atendimentos, além do grande número de alunos envolvidos, o reduzido número de profissionais tanto na área de educação, quanto na saúde, a falta de apoio técnico, foram questões frequentemente mencionadas pelas entrevistadas. Como afirma a odontóloga, "têm trezentas crianças na creche, mais quatrocentas e poucas na escola. Então, para dar conta de fazer em pelo menos [com] metade dos alunos todas as atividades que eles consideram essenciais, é muita coisa. Tem muito volume de trabalho e tu não consegues ter tempo de fazer".

Os problemas para a realização das ações são semelhantes na rede pública de ensino. Para a Diretora da EMEI, o PSE apareceu, de certo modo, como algo impositivo, com o pressuposto de "vocês que façam... tem que ser feito!", acrescentando que "não se faz nada com pouco tempo, pouco recurso". A mesma percepção manifesta uma das orientadoras educacionais, para quem o PSE foi "colocado" como mais um serviço a ser desenvolvido na escola, e os trabalhadores deveriam "se virar" para fazer. Na EMEF, as entrevistadas afirmam que existe "muita ficha, muita coisa pra preencher, uma coisa trabalhosa" (Orientadora 1).

Como a saúde não está integrada ao currículo escolar, este acaba sendo um obstáculo para o desenvolvimento das atividades, pois os professores precisam dar prioridade ao trabalho com os conteúdos previstos. A quantidade de alunos a serem atendidos por poucos profissionais constitui outro problema para o cumprimento das atividades: "não tem tempo de colocar mais ações..., 600 alunos, três turnos, sérios problemas que eles têm. As ações previstas, nem todas estão sendo desenvolvidas" (Orientadora 1).

A falta de profissionais é suprida, ao menos em parte, por estagiários da universidade. $\mathrm{Na}$ EMEF, a orientadora 2 destaca que as atividades previam a participação de trabalhadores do posto de saúde, da escola e da universidade, mas que, na prática, quem está ajudando a desenvolver o Programa são os estagiários dessa última. Mesmo que na área investigada haja algum auxílio do Núcleo de Apoio à Saúde da Família (NASF), na forma de palestras sobre temas como álcool e drogas, a percepção das entrevistadas é que as atividades só estão sendo realizadas em função do apoio da universidade.

Na opinião da Coordenadora Municipal, a atuação das trabalhadoras reflete a crise na saúde: "a gente está tendo que dar conta da assistência urgente, nem é mais assistência... [é] assistência emergencial porque é isso que se consegue fazer e fica para trás outra parte de prevenção, que é justamente a parte que o PSE trabalha".

A enfermeira queixa-se de que as coisas eram mais fáceis "em outra época", e que hoje a burocracia e a alta demanda por atendimentos consomem os trabalhadores e impedem um trabalho mais próximo da educação e da saúde com os adolescentes. Lembra que em outra ESF em que trabalhou, onde não havia PSE, "a gente tinha uma ligação maravilhosa com a escola" e que o trabalho era mais integrado do que o que desenvolve agora. 
Pelos depoimentos, podemos perceber que as condições de realização do Programa desconsideram a realidade concreta da microárea investigada: grande número de alunos, poucos profissionais, intensa demanda de atendimentos assistenciais e o currículo escolar. Assim, conforme a Coordenadora Municipal, "têm unidades que avançam por comprometimento do próprio profissional de saúde ou da educação ou da união dos dois".

No que se refere à intersetorialidade, a organização do Programa na microárea é insipiente, a exemplo do verificado em outras pesquisas (Bressan, 2014; Barreto, 2015; Santos, 2015; Sousa, 2014), ficando a responsabilidade quase que exclusivamente a cargo do setor saúde. Junior (2014) chega a afirmar que o Programa é "prescrito pelo setor de saúde para ser executado pelo setor de educação" (p. 799), não conseguindo, portanto, superar a visão setorial. Também é destacado pelos mesmos autores a falta de profissionais e as condições de trabalho desfavoráveis como aspectos que contribuem para a não realização das atividades e a ausência de intersetorialidade.

Apesar dos limites mencionados pelas trabalhadoras, elas mostram-se favoráveis ao Programa, entendendo que o mesmo está atingindo os objetivos propostos, por meio de ações como o controle de vacinação, o grupo de obesidade, o grupo para pais de crianças diabéticas, acompanhamento do índice de massa corpórea das crianças, reuniões com os pais e outras que possibilitam a formação em saúde das famílias. Conforme a Diretora da EMEI, após a implementação do PSE, "a gente tem um olhar mais para o cuidado". A maior carência em relação aos objetivos, segundo as entrevistadas, diz respeito à participação da comunidade, que ocorre de forma pouco expressiva.

No entanto, mesmo reconhecendo sua importância, cabe dizer que as ações mencionadas pelas profissionais não são suficientes para configurar um êxito do Programa. Em sua maioria, se caracterizam mais como atividades isoladas, sem integração entre equipes e comunidade.

\subsection{Formação para o trabalho no PSE: o aprendizado na experiência}

\subsubsection{Formação inicial}

Com exceção da auxiliar de saúde bucal, todas as profissionais responsáveis pelo PSE na microárea investigada possuem formação em nível superior. Três delas cursaram uma pósgraduação lato sensu, quatro concluíram dois cursos da mesma modalidade e uma cursou mestrado. Percebemos, assim, que as profissionais que atuam no Programa têm boa formação profissional e buscam aprimorar sua qualificação. $O$ apoio institucional para a realização desses estudos restringese, porém, à possibilidade de compensar as horas destinadas a tal formação.

Ainda assim as trabalhadoras não se sentem suficientemente preparadas para as atividades do Programa. As profissionais da área da saúde encontram-se numa situação melhor, já que, como parte de sua formação acadêmica, realizaram estágios e disciplinas sobre saúde na escola. Como a odontóloga, que afirma que na graduação "teve bastante contato com isso", ou a enfermeira, para quem "a gente já é preparada para os grupos de educação em saúde". A exceção é a auxiliar de saúde bucal, que diz que o curso técnico, que se caracteriza pela curta duração, não a preparou adequadamente. Contudo, o que falta a essas trabalhadoras é a formação para as práticas 
educativas. Assim, segundo as orientadoras, as profissionais da saúde têm que ser acompanhadas "por causa da nossa didática, da nossa pedagogia, que para eles falta" (Orientadora 1).

Já as trabalhadoras da educação não tiveram, em sua formação inicial, qualquer conteúdo que as preparasse para o Programa. A Diretora, inclusive, diz não ter tido disciplina específica sobre o tema saúde.

\subsubsection{Estratégias de qualificação profissional}

Com o intuito de enfrentar as carências quanto à sua formação, as trabalhadoras desenvolvem algumas estratégias, como cursos presenciais ou em EAD. No entanto, como veremos adiante, a principal alternativa é a educação informal, nas trocas de conhecimentos em experiências do cotidiano de trabalho.

Segundo a Coordenadora Municipal, após a adesão do município ao Programa foi chamado um representante de cada local (ESF, UBS e escolas) para participar de um processo de capacitação e multiplicá-lo em seu ambiente de trabalho. A ocorrência de tais encontros depende da disponibilidade da Coordenadora Municipal e da demanda de trabalho nas Unidades de Saúde e Unidades Escolares. Além dessa formação inicial, o que ocorre são outras capacitações, principalmente por meio de EAD, que a Coordenadora recebe via PSE ou via SPE (Saúde e Prevenção nas Escolas), e encaminha para os gestores da atenção básica e da educação para que multipliquem nas unidades de saúde e escolas. Segundo a mesma, os temas dessas capacitações versam sobre o uso abusivo de drogas, saúde, "coisas bem específicas de adolescente".

As limitações de tempo presentes na realização das atividades do Programa também são relatadas no que se refere às práticas de formação das profissionais. Como diz a odontóloga, "boa vontade todo mundo tem. A maioria dos que estão aqui já trabalham há anos em Saúde Coletiva. É mais a questão do tempo mesmo de conseguir dar conta de tudo".

Assim, por exemplo, conforme a Coordenadora Local, a participação em eventos, geralmente promovidos por secretarias de educação e saúde, universidade e outras entidades, ocorre "na medida do possível". Como a ESF não pode ter sua rotina alterada, uma ou mais profissionais participam do evento, geralmente as ACS, por não possuírem uma agenda pré-determinada de atendimentos e assim ter maior facilidade de interromper as atividades. Posteriormente, elas repassam as informações aos colegas de trabalho nas reuniões de equipe realizadas semanalmente.

Para a Coordenadora Local, todo e qualquer processo de capacitação é positivo, pois apesar das profissionais da saúde possuírem experiência em trabalhar com Educação em Saúde e Saúde Coletiva, alguns assuntos demandam maior conhecimento: "poderia ter mais gente de fora vindo nos capacitar, ter mais aperfeiçoamento". Ressalta que a formação das trabalhadoras é muito voltada para sua área de graduação e que ainda não ocorreram capacitações sobre assuntos específicos, destacando o tema da Saúde Coletiva.

Quanto às trabalhadoras da educação, a demanda de formação em saúde é mais significativa, sendo suas maiores carências temas considerados tabus, como os que envolvem a sexualidade e o uso de drogas, onde é necessário, segundo elas, ter "jogo de cintura". Como diz a orientadora 1, "têm alguns temas que a gente não consegue contemplar bem". Ressalta que numa situação em que desejavam abordar a sexualidade, conseguiram que viesse a Coordenadora 
Municipal e esta deu uma "palestra maravilhosa", mas lembra que foi uma situação isolada, pois geralmente não conseguem contar com profissionais. Comenta a necessidade do Programa investir mais, "fazer cursos para trabalhar sobre determinados assuntos (...) para nos ajudar aqui na escola".

As trabalhadoras das escolas também contam com atividades de capacitação para a realização do Programa, enfrentando as mesmas restrições para participar e assim também se utilizando da estratégia da multiplicação, normalmente nos espaços de reuniões: "porque a gente não tem como dispensar todo mundo, infelizmente" (Diretora EMEI).

Na EMEI, um meio encontrado para sanar as carências são os almoços pedagógicos bimestrais e as jornadas realizadas anualmente pela Secretaria Municipal da Educação. Entretanto, para a Diretora da escola, "nós teríamos que saber mais" e, segundo ela, há deficiências inclusive quanto ao conhecimento das finalidades do Programa. Em sua compreensão, a proposta do PSE deveria ser "mais coerente, mais voltada para nosso local, nosso estado, nosso município", não "uma coisa tão ampla, tão geral". Queixa-se também da ausência de acompanhamento e que "faltam muitas questões do desenvolvimento da criança que a gente não sabe, que a gente não faz por desconhecimento".

A fala a seguir da Diretora da EMEI resume bem as carências sentidas pelas profissionais no que respeita ao conhecimento para a realização do Programa:

[As] atividades de prevenção, se a gente tivesse... as mães não fazem mais a puericultura nos postos de saúde. Se tu não tens na rede particular, se no convênio a mãe não tem, elas não procuram mais os postos de saúde. A gente está com muita criança com doenças sérias de tuberculose, porque elas não fazem mais aquela ida mensal ao posto para ver o peso e a medida. E na área da educação a gente vê que ela não vai para medir a cabeça da criança (...). Então isso é saúde permanente, é programa de saúde permanente. Só que para isso tem que se gastar dinheiro, tem que ter gente para trabalhar. E tem que se ter conhecimento. E conhecimento a gente não tem (Diretora EMEI).

Retomando as estratégias de formação previstas para implementação do PSE, o que podemos perceber é que na microárea investigada elas estão longe de acontecer. $O$ curso de Prevenção do Uso de Drogas para Educadores de Escolas Públicas e a Rede Universidade Aberta do Brasil não foram mencionadas nas entrevistas quanto às práticas educativas nas quais os sujeitos têm se envolvido. Da mesma forma, não há sinais de existência do processo de formação de Jovens Protagonistas. Aliado ao não funcionamento efetivo de um Grupo de Trabalho Intersetorial, essas questões demonstram que espaços coletivos de reflexão e discussão das atividades do Programa não fazem parte da rotina das trabalhadoras.

Conforme Farias (2014), "mudanças estão sendo implementadas, mas o que pode ser observado é a escassez de capacitação e educação permanente, além da inexistência de protocolos que norteiem o desenvolvimento de ações intersetoriais" (p. 1).

\subsubsection{O aprendizado na prática profissional}


Frente às dificuldades de poder contar com práticas educativas e uma organização do trabalho que proporcionem educação permanente, as trabalhadoras do PSE da microárea investigada recorrem à educação informal, que se dá na experiência de trabalho, entre colegas, em reuniões e nas relações com os estagiários e docentes da universidade. Algo bastante significativo foi o destaque dado ao aprendizado com os alunos, constatando-se, desse modo, que alguns docentes estão superando a educação centrada no papel de um professor transmissor de conhecimentos. Como afirma a Coordenadora Municipal, "professor lida com adolescente, mas lida com adolescente numa situação de hierarquia. Onde tem que lidar, formar vínculo, trabalhar alguns assuntos mais íntimos, o professor muitas vezes não consegue, não tem essa habilidade". Segundo a mesma entrevistada, o que lhe propiciou superar a compreensão tradicional foi a experiência vivida ao longo dos anos: "na prática, no dia a dia, aprendi com os próprios adolescentes, como lidar com eles".

Para a orientadora 2, a experiência é fundamental, pois "isso eu fui adquirindo com colegas, na prática do dia a dia, [quando] nós aprendemos uma com a outra. Porque no momento que eu sempre faço uma troca, eu já penso, ah! Eu posso fazer assim, eu posso fazer diferente". As orientadoras educacionais da EMEF também ressaltam o aprendizado na experiência, especialmente quando envolve discentes e/ou docentes da universidade: "é na prática que a gente realmente aprende [...], com os acadêmicos novos, que sempre vêm com alguma ideia diferente. $A$ gente precisa muito do que vem de fora para não ficar tão bitolada aqui" (Orientadora 1). Observamos, assim, que as profissionais estão conseguindo compreender os estagiários não apenas como aprendizes, valorizando os conhecimentos acadêmicos dos quais são portadores.

$\mathrm{Na}$ EMEI, a Diretora destacou o aprendizado entre as trabalhadoras nas reuniões setoriais. A odontóloga e a agente de saúde bucal salientaram os contatos com as unidades escolares e com as demais profissionais de saúde, assim como as atualizações trazidas pelos discentes e docentes da universidade.

Apesar das dificuldades e limitações, as trabalhadoras acreditam que o PSE está conseguindo implantar a educação permanente. Conforme a Coordenadora Municipal, as profissionais da educação e da saúde devem trabalhar os componentes do Programa: "pelo menos uma vez por ano ele tem que entrar naquela turma e falar sobre aquilo. E falar sobre aquilo exige planejamento, exige encontro, exige planejamento criativo e isso puxa a educação permanente".

Porém, pelo que depreendemos dos depoimentos, a fala da Coordenadora Municipal parece revelar mais um ideal de como as coisas deveriam ocorrer do que o que de fato acontece na prática, pois planejamentos e encontros estão bastante limitados pela organização do trabalho e o reduzido número de profissionais. Esse entendimento é corroborado pelas duas orientadoras educacionais e pela odontóloga, que afirmam que as condições de trabalho influenciam negativamente para a ocorrência das práticas educativas. Esta última revela uma concepção superficial da educação permanente, restringindo sua realização às ações individuais: "eu acho que é tu estar sempre envolvida. Ou fazendo um curso, ou lendo um artigo, sempre procurando ir atrás. E também tentar transmitir, porque [não adianta] só tu ler, aprender e não passar". 


\section{CONSIDERAÇÕES FINAIS}

Os resultados do estudo reforçam a importância das ações realizadas pelas trabalhadoras de educação e saúde para o enfrentamento das vulnerabilidades sociais a que os educandos estão submetidos. Para as trabalhadoras, os educandos estão sendo melhor assistidos e eles próprios têm se tornando agentes de formação em saúde, possibilitando que suas famílias tenham acesso às informações. É positivo perceber que mesmo o Programa tendo parado de receber recursos, ele segue funcionando. Entretanto, isso acaba por exigir dos profissionais um esforço extra para que as coisas aconteçam, muitas vezes de forma precária e improvisada.

É preciso considerar que, no momento da pesquisa, o Programa estava em implantação e no seu seguimento pode trazer melhores resultados. Porém, sem uma melhoria da organização e das condições de trabalho e da ampliação do número de trabalhadores que proporcionem às profissionais melhores possibilidades de formação, elas terão que seguir contando com esforços individuais e com as possibilidades de educação informal na experiência profissional, o que não é suficiente para uma boa formação, tão pouco sendo esta a proposta do Programa. É consenso entre as demais pesquisas a necessidade de ampliação da formação para que o mesmo possa avançar de forma significativa (Bressan, 2014; Barreto, 2015; Sousa, 2014).

As limitações da formação acadêmica para o trabalho em educação e saúde poderiam ser em boa parte superadas se as trabalhadoras pudessem contar com espaços em que pudessem planejar e avaliar coletivamente as atividades. Além disso, é fundamental ampliar o Grupo de Trabalho Intersetorial, tanto em nível municipal quanto local, no sentido de contemplar a participação de professores e representantes da comunidade.

\section{REFERÊNCIAS}

Antunes, R. (2010). Adeus ao trabalho? Ensaio sobre as metamorfoses e a centralidade no mundo do trabalho. (14a ed). São Paulo: Cortez.

Barbosa, V. B. de A., Ferreira, M. de L. S. M. \& Barbosa, P. M. K. (2012). Educação permanente em saúde: uma estratégia para a formação dos agentes comunitários de saúde. Revista Gaúcha de Enfermagem, 33(1), 56-63.

Barreto, M. B. (2015). (Des)Articulação da saúde e educação no grupo de trabalho intersetorial municipal do Programa Saúde na Escola: espaços de saberes, poderes e afetos? (Dissertação de mestrado). Universidade Estadual de Feira de Santana, Feira de Santana, Minas Gerais, Brasil.

Benevides, R., \& Passos, E. (2005). Humanização na saúde: um novo modismo? Revista Interface Comunicação, Saúde, Educação, 9(17), 389-406.

Brasil (2007). Decreto n. 6.286, de 05 de dezembro de 2007. Institui o Programa de Saúde na Escola - PSE, e dá outras providencias. Diário Oficial [da] República Federativa do Brasil, Poder Executivo, Brasília, DF. 
Brasil (1971). Lei de Diretrizes e Bases da Educação Nacional. Lei no. 5.692, de 11 de agosto de 1971. Fixa Diretrizes e Bases para o Ensino de 1으 e o Graus. Brasília.

Brasil (2011). Ministério da Saúde. Secretaria de Atenção à Saúde. Departamento de Atenção Básica. Instrutivo PSE. Brasília.

Brasil (2018). Presidência da República. Casa Civil. Lei no 13.595, de 5 de janeiro de 2018. Dispõe sobre as atribuições, a jornada e as condições de trabalho, o grau de formação profissional, os cursos de formação técnica e continuada e a indenização de transporte dos profissionais Agentes Comunitários de Saúde e Agentes de Combate às Endemias. Brasília.

Brasil (1969). Ministério da Saúde. Portaria Interministerial no 1.055, de 25 de abril de 2017. Redefine as regras e os critérios para adesão ao Programa Saúde na Escola. Brasília.

Brasil (2004). Ministério da Saúde. Secretaria-Executiva. Núcleo Técnico da Política Nacional de Humanização. HumanizaSUS: Política Nacional de Humanização: a humanização como eixo norteador das práticas de atenção e gestão em todas as instâncias do SUS. Brasília.

Bressan, F. (2014). O Programa Saúde na Escola: interfaces entre saúde e educação no município de Blumenau, SC. (Dissertação de Mestrado). Universidade Regional de Blumenau, Blumenau, Santa Catarina, Brasil.

Ceccim, R. B. (2005). Educação permanente em saúde: desafio ambicioso e necessário. Interface Comunic, Saúde, Educ, 9(16), 161-77.

Dedecca, C. S. \& Trovão, C. J. B. M. (2013). A força de trabalho no complexo da saúde: vantagens e desafios. Revista Ciência \& Saúde Coletiva, 18(6), 1555-1567.

Farias, I. C. V. de. (2014). Análise da intersetorialidade no Programa Saúde na Escola no município de Olinda-PE: perspectivas da saúde e da educação. (Dissertação de mestrado). Universidade Federal de Pernambuco, Recife, Pernambuco, Brasil.

Filho, S. B. S. \& Barros, M. E. B. de. (2012). O trabalho em saúde e o desafio da humanização: algumas estratégias de análise-intervenção. Revista Tempus Actas de Saúde Coletiva, 6(2), 101-122.

Hennington, É. A. (2008). Gestão dos processos de trabalho e humanização em saúde: reflexões a partir da ergologia. Revista Saúde Pública, 42(3), 555-561.

Hirata, H. (2011). Tendências recentes da precarização social e do trabalho: Brasil, França, Japão. Caderno $C R H, 24(1), 15-22$.

Junior, A. J. da S. (2014). Programa Saúde na Escola: limites e possibilidades intersetoriais para o desenvolvimento do autocuidado. (Tese de doutorado). Universidade Federal de Mato Grosso, Cuiabá, Mato Grosso, Brasil.

Marinho, M. N. A. de S. B. (2014). Programa Saúde nas Escolas (PSE) na região metropolitana do Cariri: dos processos formativos aos cenários de práticas. (Dissertação de Mestrado). Universidade Estadual do Ceará, Fortaleza, Ceará, Brasil. 
Mattos, M. de, Veronesi, C. L. \& Silva Junior, A. J. da (Org). (2013). Enfermagem na educação em saúde. Curitiba: Prismas.

Miccas, F. L. \& Batista, S. H. S. da S. (2014). Educação permanente em saúde: metassíntese. Revista Saúde Pública, 48(1), 170-185.

Pinsky, C. B. (2013). A era dos modelos rígidos. In C. B. Pinsky, \& J. M. Pedro (Org). Nova história das mulheres no Brasil. (pp. 469-512). São Paulo: Editora Contexto.

Santos, N. P. dos. (2015) Promoção da saúde do escolar adolescente segundo as diretrizes do Programa de Saúde do Escolar: uma experiência em um município do sul do Brasil. (Dissertação de Mestrado). Universidade Federal do Paraná, Curitiba, Paraná, Brasil.

Silva, C. dos S. \& Bodstein, R. C. de A. (2016). Referencial teórico sobre práticas intersetoriais em Promoção da Saúde na Escola, Revista Ciência \& Saúde Coletiva, 21(6), 1777-1788.

Sousa, M. C. de. (2014). Saúde na Escola: analisando os caminhos da intersetorialidade. (Dissertação de Mestrado). Universidade Federal da Bahia, Salvador, Bahia, Brasil. 